\title{
A INVENÇÃO DO ECOMUSEU: O CASO DO ÉCOMUSÉE DU CREUSOT MONTCEAU-LES-MINES E A PRÁTICA DA MUSEOLOGIA EXPERIMENTAL*
}

Bruno Brulon

Un écomusée, ce n'est pas un musée comme les autres. ${ }^{1}$

Georges Henri Rivière

"Alguma coisa se modificou com o movimento da descolonização", afirma François Mairesse (2002:101) ao tratar da "nova museologia", movimento que eclodiu na França nos anos 1980, aliado às novas experiências de museus que já vinham sendo colocadas em prática desde os anos 1960. De fato, a descolonização dos museus, à qual se referiram alguns museólogos que pretendiam fazer uma museologia de vanguarda, diz respeito a um conjunto de conceitos que tinham o objetivo de revolucionar a prática museológica do final do século XX, tais como o de "participação da coletividade", ou o de "identidade cultural". Tais noções não foram incorporadas a discursos museológicos e às ideologias apenas nos países periféricos; ao contrário do que se pode pensar, elas tiveram suas primeiras aparições a partir de experiências inovadoras entre os museus dos países industrializados. ${ }^{2}$ O projeto central que se impõe ao "novo museu", segundo Mairesse, consiste na busca pelas "origens" de uma cultura submersa, "seja ela rural ou industrial, das periferias ou de favelas" (Mairesse 2002:103). Por envolverem um tipo de imersão das pessoas em sua própria cultura e um contato íntimo com a memória, esses museus tiveram que contar com o suporte da etnologia e, de fato, se desenvolveram como uma alternativa iconoclasta aos museus etnográficos clássicos, principalmente por romperem com a lógica do olhar do Outro sobre o patrimônio ali apresentado.

Tendo como berço a França pós-colonial, em sua origem o "ecomuseu" representou a utopia da democratização da memória, por meio de um mecanismo museológico inclusivo que tinha por objetivo principal o de dar a palavra àqueles que apenas raramente partilhavam da cena da História. 
Este museu de vanguarda, nos anos 1970 e 1980, voltou-se para aquelas que haviam sido consideradas até então as "culturas dos Outros", culturas silenciadas e deixadas à margem de qualquer tipo de musealização. O ecomuseu é "inventado" no momento em que um novo discurso sobre a ideia antropológica de cultura é formulado, o momento da disseminação de uma contracultura, e da emancipação da cultura popular na Europa. Em regiões do dito "terceiro-mundo" como a América Latina, novas expressões de museus que rompiam com o modelo clássico importado pelo sistema colonial começam a ganhar ênfase e a interrogar a "museologia tradicional"3 — que tinha como paradigma o modelo de museu tradicional, fechado em suas próprias coleções materiais, atendendo aos valores específicos das elites culturais. A cultura no sentido antropológico do termo se sobrepõe à cultura erudita das elites, que até então dominava a cena dos museus.

As novas ideias que sustentavam o modelo do ecomuseu provinham, por um lado, da insatisfação de alguns pensadores franceses em relação à museologia tradicional, que começaram a colocar em prática museus com uma finalidade descentralizadora e, por outro, da influência de certas experiências de museus heterodoxos ou de "vanguarda" nas ex-colônias. Em meio a este contexto de rupturas, o projeto "ecomuseológico" visava permitir que a memória recolhida pelos etnólogos fosse restituída ao conjunto do grupo através de diversos instrumentos, sendo a exposição de objetos materiais apenas uma expressão possível (Chaumier 2004:66). Um dos primeiros museus pensados com o objetivo explícito de romper com os entraves da museologia "restrita" e fragmentária, que vinha sendo colocada em prática nos museus tradicionais franceses, seria criado em uma importante região industrial, completamente à margem de qualquer referência à dita "alta" cultura.

Este artigo apresenta a investigação histórica do Écomusée du Creusot Montceau-les-Mines, primeiro ecomuseu a ser reconhecido como tal, criado em 1974, em uma comuna da Borgonha, na França, que até hoje se beneficia cultural e economicamente da produção industrial local, cuja importância provém de uma história de esplendor interrompida por uma crise econômica seguida do abandono pelos principais agentes do patrimônio local. A partir da pesquisa histórica realizada entre 2011 e 2012 e da entrevista com alguns dos porta-vozes que participaram dessa experiência museológica nos anos em que ela foi considerada precursora, foi possível notar o sentido emocional das relações estabelecidas com e na "comunidade urbana"4 do Creusot, no processo em que, em função da "invenção" de um novo tipo de museu, se buscou instaurar uma nova "gramática axiológica" (Heinich 2012:19) local, por meio de uma gramática museal. 


\section{O Écomusée du Creusot Montceau-les-Mines: o início de uma gramática museal experimental}

A ideia de um museu para o Creusot surgiu no início dos anos 1970, quando Marcel Évrard (1921-2009), após concluir diversas expedições ao redor do mundo, realizando principalmente coletas de objetos de arte primitiva para alimentar museus e galerias na França, retorna à sua propriedade na Borgonha. Sua esposa, Michele Évrard (1929-2007), que era originária da região, atravessava uma doença grave, o que fez com que os dois permanecessem naquela localidade. Mais tarde, os laços estabelecidos por eles com a comunidade do Creusot os levariam a se envolver intimamente com a experiência do ecomuseu.

Reconhecido no campo museal francês por ter trabalhado, em um momento anterior, na organização de exposições no Musée de l'Homme e, simultaneamente, tendo colecionado objetos de arte primitiva e mantido relações estreitas com galeristas e outros colecionadores, alimentando a sua dupla paixão pela arte e pela etnologia, Marcel Évrard era uma personalidade que percorria diversos universos interpretativos com o mesmo entusiasmo pela descoberta e a inovação. Nos anos em que manteve tal proximidade com o Creusot, ele se dispôs a organizar diversas exposições, fosse de arte primitiva, fosse de arte contemporânea, nos espaços públicos locais, como salões de festa e as salas da prefeitura. Nesses eventos, Évrard iria se beneficiar do Centro de Ação Cultural (o CAC, ligado ao centro de Lazeres, Artes, Encontros e Cultura - LARC ${ }^{5}$ ), criado no Creusot a partir de uma iniciativa de membros da população local, com um propósito de descentralização e de animação cultural, e que funcionava como uma Casa de Cultura sem estruturas permanentes. Ao assumir a sua presidência, um dos militantes da cidade, conhecido como doutor Jo Lyonnet, tendo o propósito "marginal" de dar subsídio aos artistas locais, ${ }^{6}$ convida Évrard, como a primeira personalidade exterior à municipalidade do Creusot, para participar do que seriam as atividades que antecederiam o futuro ecomuseu.

Vislumbrando as experiências já realizadas no seio da comunidade, e tendo em vista a presença de Évrard no Creusot, o prefeito da cidade, Henri Lacagne (1909-1993), propõe a ele, a partir desta estrutura cultural já iniciada, a criação de um museu. Mas que museu poderia criar Évrard diante do desconhecimento por parte da população local do seu próprio patrimônio e da sua história? Que linguagem adotaria esta nova instituição e como seria organizada?

Em 1970, tendo já criado o Cracap, Centro Nacional de Pesquisa de Animação e de Criação para as Artes Plásticas, ${ }^{7}$ Évrard precisava ainda de 
um espaço físico para acolher tal estrutura. Nesse momento, a prefeitura do Creusot lhe oferece o Château de la Verrerie, antiga residência dos Schneider - família que comandara na região um "império" industrial até meados do século XX - com a condição de que ele criasse ali um museu para a cidade. A ocupação do antigo castelo, símbolo da indústria no Creusot, representava o início da reapropriação do patrimônio local de acordo com uma gramática museal.

Segundo uma sociologia dos valores, como pensada por Nathalie Heinich (2009), o patrimônio em si mesmo pode ser entendido como uma categoria valorizada, de modo que o simples fato de se categorizar um artefato como patrimonial significa que a ele é atribuído um valor (Heinich 2009:151). Com efeito, é possível perceber o domínio patrimonial como indissociável de uma abordagem axiológica, já que, como ficou evidente no caso do museu do Creusot, ele inevitavelmente envolve o julgamento de valor pessoal ou coletivo e um conjunto de emoções do grupo que enquadram a seleção do patrimônio. O processo de criação do ecomuseu tratou de um alargamento progressivo do campo nocional dos objetos do patrimônio avaliados e/ou valorados (Heinich 2012:19) pela população do Creusot, que deixava de interpretar os seus próprios bens a partir de um sistema de valores disseminado pelas elites das metrópoles culturais para interpretá-los de acordo com os seus próprios valores e a sua autoavaliação mediada pelos agentes do museu.

Como parte da condição que fora imposta a Évrard, em contrapartida à apropriação do Château de la Verrerie, o Cracap deveria se encarregar ele mesmo da concepção, da criação e da animação do futuro museu. Essa mudança prefigura a criação de um museu em que o discurso sobre a arte iria se misturar com aquele sobre a história industrial (Debary 2002:30). Évrard concilia a lógica desses dois projetos explicando que "desde que o Cracap aceitou ser encarregado da criação de um museu local, ele pensava em responder à sua vocação de descentralização e de sensibilização às Artes plásticas em um meio dado" (Évrard 1974:1). A originalidade do projeto estaria justamente na união, até então inusitada, da arte, da história e da etnologia em um só discurso museal e, com efeito, a novidade de uma abordagem da história industrial conjugada com uma démarche artística estaria no espírito da estrutura dirigida por Évrard. Aqui, diferentemente do que acontecia tradicionalmente nos grandes museus da capital, nos quais, muitas vezes, a arte era responsável por excluir, a proposta inversa é colocada em prática, e a abordagem artística é utilizada para trazer aqueles indivíduos que se encontravam na margem para o seio do museu e de sua própria sociedade. 
Rapidamente o projeto passou a chamar a atenção de outras personalidades que marcariam a história do Creusot - tais como Hugues de Varine (1935-), Georges Henri Rivière (1897-1985) e Mathilde Bellaigue (1932-), que seriam atraídos ao trabalho museológico desenvolvido por Évrard justamente pela inovação da linguagem museal, que unia a abordagem dos "museus de sociedade" ${ }^{\text {a }}$ uma abordagem de museus de arte. Tal inovação decorreu principalmente do fato de que, como constataram Évrard e Varine, ${ }^{9}$ nas primeiras discussões sobre o ecomuseu, localmente, um museu clássico não interessaria às pessoas, ainda que pudesse ser difícil que um museu de tipo indefinido fosse reconhecido pela Direção dos museus da França, como se provou mais tarde (Debary 2002:205). Logo ficou claro que a base do museu estaria nas pessoas, e ele não seria alvo de preocupações - ao menos inicialmente - com a constituição de coleções. Pouco importava o que seria reunido para colocar em prática os objetivos do museu, porque o que dava vida ao projeto era a existência mesma de tais objetivos preliminares. Estes eram repartidos em dois propósitos primordiais: o do desmantelamento do paternalismo industrial estabelecido ao longo da história, em primeiro lugar, e o da participação e da criação da comunidade urbana do Creusot como uma "entidade autônoma", em segundo.

Ao buscar um caráter interdisciplinar para o empreendimento, Évrard decide que a melhor maneira de colocá-lo em prática é dando aos habitantes do Creusot, vitimados historicamente por um passado de dominação, a chance de tomar parte em suas próprias narrativas. Mathilde Bellaigue, que aderiu ao projeto como assistente de Évrard a partir de 1976 e permaneceu até 1984, testemunhou de forma sensível os efeitos de uma história de desvalorização da população do Creusot através do desenvolvimento da indústria. Ela afirma que "eles [os habitantes] tinham conhecimento da história do Creusot, do fato de que o Creusot havia feito uma parte da Torre Eiffel, a grande estação de Santiago do Chile, e o famoso Marteau-pilon do Creusot", elementos ligados à história da grande indústria local, "mas o desenvolvimento de sua própria história eles desconheciam, pensavam não ter importância" (informação verbal). ${ }^{10}$ Assim, a força impulsora do trabalho de Évrard e de outros agentes externos que atuaram ao seu lado era uma necessidade evidente de autonomização de uma memória e de um patrimônio que não eram reclamados por seus herdeiros em razão de uma estrutura de poder rigidamente hierarquizada que se estabelecera ali por décadas.

Desde 1836, quando os irmãos François e Joseph-Eugène Schneider assumiram as minas, as forjas e as fundições do Creusot, ${ }_{1}^{11}$ o pequeno vilarejo de 800 habitantes se desenvolveu como uma empresa que, por sua expansão, iria se tornar uma das mais importantes da França no século XIX. Durante quatro 
gerações o destino dos Schneider se ligaria a essa localidade. Em 21 de outubro de 1836 eles criaram "uma sociedade em comandita por ações" (Debary 2002:19), e se tornaram os gestores e os responsáveis da sociedade sobre seus bens pessoais. Essa estrutura jurídica iria confundir as responsabilidades e os interesses de uma família com aqueles de uma empresa. A partir desta apropriação paternalista, a história do Creusot, depois do século XIX, se viu reduzida, na maioria dos pontos de vista, à história da genealogia dos Schneider. Como aponta Debary, a onipresença dos Schneider no local é marcada pela presença de monumentos: estátuas dos Schneider dividem o espaço das forjas; diversas igrejas foram batizadas com o primeiro nome de cada um dos patriarcas (Debary 2002:22). O espaço político do Creusot também não escapou dessa dominação e, apesar de os Schneider não ocuparem eles mesmos os cargos de prefeito ou de deputado, eram membros da empresa próximos a eles que o faziam. Eles representavam uma família, uma empresa e toda uma cidade.

Com a crise da indústria e a morte de Charles Schneider (1898-1960) a família que comandava o complexo urbano do Creusot deixa a localidade órfã, de modo que a recomposição do espaço industrial conduz a um desmantelamento do paternalismo que perdurara por quatro gerações (Debary 2002:15). Para que não morressem, as práticas ligadas às atividades de produção se transformam em práticas assinaladas como "culturais e patrimoniais". Sob a ameaça da morte dos restos do passado, a solução foi fazer um museu para que estes permanecessem vivos.

Como performance de uma memória coletiva em permanente evolução, o ecomuseu não podia se equiparar a nenhum dos moldes preestabelecidos. Segundo Évrard, a experiência do museu do Creusot era "demasiadamente experimental, e muito pragmática" para ser enquadrada à de outros museus existentes (Évrard 1976:9). Com efeito, ele partilhou com os parques naturais a preocupação ecológica, mas não se limitou a ela; além disso, o museu nasceu com uma preocupação artística fundadora, mas não se restringiu às exposições de arte. Como constata seu maior idealizador, a originalidade do ecomuseu do Creusot reside em sua ambição. Ele visava ao desenvolvimento cultural de uma população que, durante um século e meio viveu as transformações, as trocas e as tensões dos mundos agrícola e industrial, rural e urbano (Évrard 1976), enfim, um grupo social em permanente mudança, e que teria, em tese, que desenvolver os próprios meios de lidar com o seu patrimônio e a sua memória.

Mas, na prática, que meios seriam estes? Em 1971, a municipalidade aprova uma convenção com Évrard para a criação "de um museu do Homem e da Indústria". ${ }^{12}$ Ele passa, então, a procurar pessoas para auxiliá-lo. Em abril do mesmo ano ele se encontrara pela primeira vez com Hugues de 
Varine, em um colóquio nacional sobre arte moderna e museus de província em Saint-Maximin. Varine, então diretor do Conselho Internacional de Museus (ICOM), seria colocado a par do projeto de museu em seu estágio inicial. Ele mesmo originário da Borgonha mostrou interesse pelo desafio que se apresentava; convencido do papel de animação que poderia dar a esse empreendimento, Varine decide se associar ao projeto, passando a participar de reuniões com Évrard e Lyonnet, no Creusot, além de realizar entrevistas com outras lideranças locais.

Nessa ocasião, o problema da institucionalização do "ecomuseu" já se apresentava, uma vez que na França ele não poderia existir sem a tutela de um ministério. Varine, em busca da legitimação da nova ideia (indefinida) de museu, estabelece uma discussão sistemática sobre o termo em âmbito nacional entre os especialistas e profissionais de museus, criando colóquios e convidando pessoas a tomar parte no novo debate que se estruturava. No cargo de diretor do Icom, antes ocupado por Rivière, é ele quem o mantém em constante contato com o projeto do ecomuseu ${ }^{13}$ e com a nova forma de se fazer museologia que se pretendia colocar em prática. Não demoraria para que Rivière também aderisse ao projeto no Creusot.

Em 1973, ao lado de Marcel Évrard, Rivière faz o "Primeiro esboço de uma programação museológica" (Bellaigue-Scalbert 1989:164), enquanto Varine elabora um conjunto de proposições de atividades que concretizariam a implantação do "ecomuseu" na comunidade, ao qual ele se referiria como "musée éclaté". ${ }^{14}$ Criada naquele mesmo ano, a associação do Écomusée de la Communauté Urbaine du Creusot Montceau les Mines - Musée de l'Homme et de l'Industrie se estabeleceu com o fim de promover a participação da população da comunidade urbana, além do planejamento e do desenvolvimento da comunidade, considerando "a originalidade de seus membros e a diversidade de seus interesses" (Estatuto do Ecomuseu da Comunidade Urbana do Creusot Montceau les Mines, 1973).

O ecomuseu é criado na forma de uma associação, por meio de um estatuto a ela referente, diferenciando-se dos museus reconhecidos pelos poderes públicos por seu caráter não permanente, já que associações podem ser desfeitas quando deixam de cumprir a sua função original. Ela foi pensada como uma instituição de caráter convidativo às coletividades locais e vizinhas, abrindo as diversas vias possíveis para a participação almejada pelos idealizadores do projeto do ecomuseu. Nesta abertura estava depositada não apenas uma esperança de reconquista do patrimônio local do Creusot por seus habitantes, mas também a possibilidade de uma reviravolta na museologia francesa e mundial, uma vez que os criadores da noção do "ecomuseu" viam nele uma alternativa à estrutura autoritária e elitista da 
museologia tradicional. A associação que institucionalizaria o ecomuseu na prática tinha assim uma autonomia relativa que lhe permitia apropriar-se do patrimônio local e utilizá-lo como bem desejassem a "comunidade" e as organizações associadas.

Toda uma estrutura institucional fora criada, cujo objetivo principal era dar acesso à coletividade aos meios de apropriação do patrimônio, e comportar uma suposta vontade patrimonial que se engendraria no grupo a partir da criação do museu. A memória da coletividade se tornaria a memória da comunidade urbana, funcionando como a alma do ecomuseu e servindo aos interesses de um grupo que buscava sair da posição de subalterno para reorientar a sua identidade. Uma contradição, ao menos, era evidente: este, que parecia ser um projeto de "museu participativo" ideal, teria em seus patronos externos os seus principais porta-vozes.

Em alguns anos, Rivière e Varine viriam a ser reconhecidos como os mais ativos promotores do ecomuseu da comunidade do Le Creusot-Montceau-les-Mines, criado por Évrard e dirigido por ele até 1983. Desde o momento em que Rivière adere à ideia pioneira de reconciliar a criação artística e o fenômeno estético com o meio industrial (Bellaigue-Scalbert 1989:164), ele toma para si a tarefa de dar sentido ao empreendimento e de definir esse projeto aparentemente ambíguo. Criador de três definições distintas para o termo "ecomuseu" - que ele chamou de "definição evolutiva" — Rivière via no Creusot um verdadeiro laboratório para uma museologia sem precedentes.

\section{A transformação axiológica: os regimes de qualificação do patrimônio no Écomusée du Creusot}

O processo de descolonização da museologia ${ }^{15}$ e dos museus que se desenhou, na França a partir dos anos 1960 e 1970, significou, como se pode notar na microanálise do caso do Écomusée du Creusot, uma descolonização dos valores mais do que a descolonização das coisas. Para compreender a "gramática axiológica" que se buscou instaurar no Creusot, é preciso pensar o ecomuseu como um instrumento de mudança de valores, e que, para tanto, tratou de alterar no seio do grupo o próprio "regime de qualificação" (Heinich 2012), entendido aqui como a ossatura da "gramática axiológica" associada ao patrimônio.

A noção de "gramática", introduzida por Boltanski e Thévenot (1991) nas ciências sociais, se aplica aos princípios de avaliação praticados pelos atores para qualificar um ato, um objeto ou uma pessoa. Tal perspectiva direciona o foco da presente análise para aquilo que os atores têm em comum e, 
considerando o museu como agente coletivo em si mesmo, ela permite que se evidenciem os meios pelos quais objetos de diferentes ordens passam a ser valorados como patrimônio da comunidade.

A história do Écomusée du Creusot se deu, na visão de alguns autores, no seio de uma "inflação patrimonial sem memória" (Debary 2002:9). Segundo Debary, que etnografou a realidade da comunidade urbana e investigou o sentido do ecomuseu quando este já havia perdido algumas de suas características primárias, a "acomodação dos restos" que aconteceu no Creusot a partir do momento em que se decidiu fazer da população local, ela mesma, museu simultaneamente uniu, no processo de musealização que se seguiu, uma performance do passado e o anúncio de sua morte:

Os teatros da memória se vestem como mesas de exumação, em que o gesto patrimonial parece conservar da história apenas os seus restos insacrificáveis. Os restos protestam, se organizam e desafiam um presente que trabalha para esquecê-los sem cerimônia, sem homenagem. A alquimia patrimonial pretende conjurar a morte, mas essa reciclagem está no fundamento de uma economia (uma partilha de riquezas) reduzida a não ser mais do que uma ecologia: uma partilha do resto das riquezas (tradução nossa) (Debary 2002:10). ${ }^{16}$

Opondo-se drasticamente à mera "musealização da morte", do fim da indústria no Creusot, o ecomuseu buscou colocar em prática uma atividade museológica fundada nas pessoas, que envolveria artistas, especialistas e trabalhadores na produção de uma só performance, sem dissonâncias enquanto ela durasse. No entanto, o museu precisaria engendrar um novo tipo de musealização, cujo objetivo era a construção de outro "regime de qualificação", colocando em primeiro plano os valores do grupo, e não o de agrupar objetos em função dos interesses de um curador ou de um regime patrimonial preestabelecido. O que o projeto museológico de Évrard e seus colegas buscava realizar era a passagem de um "regime de singularidade", que valorizava aquilo que é raro, excepcional e fora do comum (como a grandiosidade do patrimônio industrial dos Schneider), para um "regime de comunidade" (Heinich 2012:31), que valorizaria o que é amplamente compartilhado no grupo (como os hábitos cotidianos da comunidade, seus meios de subsistência, sua relação com o trabalho e a indústria, e a arte local).

Aqui, a própria noção de "comunidade", passível de problematizações a partir da ótica da antropologia contemporânea, adquire um sentido próprio, e o termo passa a ser utilizado pelo grupo local para organizar em um só regime os valores que são comuns no grupo e, logo, podem servir para identificá-lo como tal. 
A constituição do patrimônio comunitário, segundo a abordagem adotada por Évrard, era fundada na investigação daquilo que tinha valor e significado, não para os especialistas ou para os conservadores envolvidos no projeto de museu, mas para a própria população local. O patrimônio, assim, começava com uma pergunta e não com um acervo ou coleção pré-constituída por valores Outros, de outro tempo, ou de outras pessoas. É por esta razão que o próprio Évrard iria defini-lo como "um museu de questões" (Évrard 2010 [1980]). Depois, quando o ecomuseu passasse a funcionar com o apoio e a colaboração de membros da comunidade, este patrimônio comunitário seria utilizado como suporte e material de ação do ecomuseu, um patrimônio apropriado no sentido de interrogar o grupo e ajudá-lo a encontrar as suas próprias respostas sobre o passado, a história e o valor mesmo de seu patrimônio.

Em 13 de janeiro de 1970 é criada oficialmente a Comunidade Urbana do Creusot-Montceau-Les-Mines (CUCM). Com a ausência de objetos para serem expostos, o museu, que até então existia apenas através do Cracap, seria obrigado a repensar o seu projeto. Sua identidade administrativa é redefinida na forma de um reagrupamento intercomunal. Cria-se a noção de "comunidade" como objeto: as comunidades urbanas (instituídas por lei desde 1966) visam fazer "coincidir as instituições administrativas das grandes cidades com as realidades práticas da urbanização" (Évrard 2010 [1980]:33). Logo, na tentativa de se corresponder o espaço do ecomuseu ao da comunidade urbana, a ideia do museu delimitado por um prédio se estende ao território. Desde 1973, Varine afirma que "a comunidade inteira constitui um museu vivo em que o público se encontra em permanência no interior" (Varine 1973 apud Debary 2002). Na falta de atores para a revolução que se propunha com a nova noção de "museu", a "população" seria mobilizada por seus membros mais ativos, aqueles que iriam se tornar a base local de implantação do novo trabalho museológico. Varine reforçaria a importância desses membros para a revolução no grupo.

Por tudo isso, ainda que sejam raros os casos de ecomuseus sem coleções de objetos materiais, eles, em geral, não se desenvolvem originalmente através das coleções, mas sim de uma memória local coletiva. Antes de uma coleção, de um prédio, e de uma vontade de museu, havia um território. É a partir da etnografia do espaço delimitado da "ville du Creusot" que se desenvolve o ecomuseu. O termo "ecomuseu", para Bellaigue, associa "meio" e "memória" (Bellaigue-Scalbert 1983:34). A territorialidade do ecomuseu, assim, não é geral, ela é local, e está ligada a uma coletividade e a uma memória coletiva particular. Neste sentido, a própria ideia de museu colocada em prática no Creusot não é aplicável a nenhuma generalidade, pois o ecomuseu é o museu 
de alguns, ele é coletivo mas fragmentário - e ele se contrapõe a qualquer tentativa de universalização dos museus. Ele é um museu sob medida, porque está balizado pelos valores que são comuns ao grupo.

No início da década de 1970, a dificuldade de constituir coleções, encontrada pelos dirigentes do futuro museu, assim como a vontade de promover um trabalho em associação com a "população" local implicavam uma transformação das estruturas jurídicas habituais dos museus. Assim, pode-se afirmar que a pretendida revolução cultural estava condicionada por uma revolução estrutural do museu. Os primeiros estatutos do museu faziam repousar a sua organização sobre um quadro associativo gerado por um conselho de administração composto por três comitês: um "comitê de usuários" (do qual faziam parte os representantes da população, encarregados de estabelecer o programa do museu e avaliar os resultados), um "comitê científico" (encarregado de realizar as atividades e de garantir o controle da pesquisa) e um "comitê de gestão" (responsável pelo financiamento e o controle administrativo). O comitê dos usuários era composto por membros que se afiliavam através das diversas associações, como as organizações profissionais, as organizações da juventude, ou outras; o comitê científico tinha membros que se dividiam em diferentes categorias (ciências exatas, tecnologia; ciências da terra; ciências do Homem, Arte; museologia; arquivística), enquanto o comitê de gestão era composto de representantes de organizações que financiavam o ecomuseu (entre eles, aqueles das coletividades locais, dos departamentos ministeriais e do setor privado).

Essa estrutura resultava no fato de que as deliberações do conselho da administração relativas às aquisições, às trocas e às alienações de objetos necessárias para o objetivo do museu deviam ser aprovadas por uma Assembleia Geral, composta de diversos membros de dentro e de fora da comunidade (Estatuto do "Ecomuseu da Comunidade Urbana do Creusot Montceau les Mines", 1973). Na medida em que o ecomuseu passou a reunir objetos materiais como coleções em benefício da comunidade local e cuja seleção dependia dos valores comuns ao grupo, esse patrimônio apresentou, por sua vez, algumas particularidades. Por definição, o patrimônio é interior à comunidade, e o ecomuseu se baseia na imposição de um código definido para conduzir a percepção deste patrimônio no território em que ele se encontra através dos símbolos da unidade da cidade, que se tornam, em muitos casos, monumentos históricos (a igreja, a casa comunitária, o castelo, a praça etc.). A avaliação, neste sentido, se transforma em um tipo de reflexão coletiva, uma vez que os agentes responsáveis pela estruturação e pela ação do ecomuseu atuam sobre as mentalidades. A população assume o papel de avaliadora de seu próprio patrimônio, e os indivíduos são levados a ultrapassar o gosto 
pessoal e a susceptibilidade para alcançar critérios e apropriações coletivas deste patrimônio segundo um novo regime comunitário.

Sobre um objeto musealizado no ecomuseu, o direito de uso de seu proprietário original permanece intacto quando um bem passa a pertencer à comunidade. Pelo simples fato de ser patrimônio da comunidade, o objeto existe sob a égide de um direito moral que é reconhecido progressivamente pelo grupo. O seu proprietário, no sentido tradicional do termo, pode continuar a utilizá-lo livremente, sem que o seu uso venha a trair os interesses do grupo. A grande novidade, neste sentido, é a existência de um museu que musealiza as coisas do real mantendo-as em suas vidas usuais, no cotidiano.

Para agir sobre o meio ambiente global, o ecomuseu do Creusot manifesta as preocupações museológicas habituais: inventário, salvaguarda, conservação, valorização do patrimônio cultural, este entendido no sentido mais vasto do termo, pertencente a todas as camadas da população (Évrard 1976:9). Em muitos sentidos, como se pode ver, o ecomuseu é um museu como os outros. Ele se distingue não em sua forma ou no tratamento dado ao patrimônio, mas no ato mesmo da musealização. Seu foco não está na constituição de coleções, mas no trabalho com as pessoas, como fica explicitado no depoimento de Mathilde Bellaigue: "Partíamos do princípio de que não precisávamos de coleções, porque se nós trabalhamos com as pessoas, as pessoas poderiam nos emprestar os objetos e, eventualmente, nos doar (informação verbal)". ${ }^{17}$

Os primeiros objetos materiais que passaram a fazer parte do ecomuseu foram adquiridos por meio de doações de membros da população local, ou sobretudo por empréstimos, quando um dado objeto era do interesse geral daqueles que respondiam pela associação para figurar em exposições temporárias. Progressivamente, como aponta Bellaigue, com o trabalho de valoração do patrimônio local, mais e mais pessoas telefonavam para o museu para oferecer doações. Diante de um número elevado de ofertas, foram definidos alguns critérios para a entrada de novos objetos na coleção. Tais critérios eram guiados, especialmente, pelo interesse por diferentes tipos de objetos que ajudassem a contar a história das pessoas e fizessem referência à sua memória, no contexto da indústria e da vida local. Bellaigue assegura que os critérios de aquisição de objetos pelo museu estavam estreitamente ligados às pessoas. "O critério era o de representar algo para as pessoas", como afirma ela, "uma lembrança, uma história, um saber-fazer" (informação verbal). Pressupunha-se que eles deveriam ser objetos de discussão para a comunidade.

Tendo como base o princípio adotado por Marcel Évrard, segundo o qual toda obra - fosse ela um trabalho industrial ou uma escultura de um artista local - poderia "ser considerada e compreendida como tão importante 
quanto uma obra de arte conhecida" (informação verbal), Bellaigue e o restante da equipe do museu também levaram em conta os critérios estéticos. A pergunta que Évrard se colocava era "como algumas coisas podem ser vistas pelo olhar do artista?", e a ideia era a de que as coisas expostas fossem também objetos de contemplação e que através deles as pessoas desenvolveriam orgulho de sua história e de seu patrimônio. Os restos da indústria, por exemplo, virariam obras de arte e monumento em praça pública. Assim, o objeto musealizado deveria "atrair o olhar", transformando progressivamente a história de depreciação e vergonha em um motivo positivo de participação. O papel do objeto belo no "regime de comunidade" instaurado era o da disseminação de uma estética ligada ao imaginário coletivo interiorizado no grupo - ou que era pensado desta maneira pelos idealizadores do museu.

Após o nascimento do ecomuseu — e da instauração da "comunidade urbana" - o desafio que se apresentou aos animadores do novo estabelecimento foi o de envolver a população local em uma nova relação com o seu meio urbano. A residência dos Schneider e seu parque foram finalmente abertos ao público, mas esses espaços permaneciam marcados pela força de uma interdição histórica. Como evidencia Jean Christophe Combier, então presidente do ecomuseu, "nós abrimos o castelo, mas as pessoas não ousam entrar" (Debary 2002:48). Assim, antes que fossem organizadas exposições permanentes no Château de la Verrerie, antes de se ocupar de forma definitiva este espaço, foram organizadas exposições de passagem, ao ar livre. Foi colocada em exposição, por exemplo, a história das árvores, com o propósito de fazer com que as pessoas se rendessem ao pretexto ecológico para se darem o direito de entrar no castelo. O objetivo era o de transformar as relações das pessoas com o território a partir de uma reapresentação das coisas no território, isto é, fazer com que o campo dos objetos avaliados e/ou valorados como patrimônio fosse alargado no sentido daquilo que as pessoas têm em comum umas com as outras ${ }^{18}$ (e aí está a dimensão pragmática do ecomuseu na construção de valores no grupo).

Ao contrário do que fazem pensar algumas vertentes da museologia, o ato da musealização, como demonstrado nas experiências com o patrimônio que se seguiram ao primeiro ecomuseu, não é um atestado da morte, mas uma maneira de fazer viver novos valores. Como ficou provado no Creusot, nos anos em que as pessoas do grupo participaram das ações do museu, por meio das associações e pelo impulso da força criadora que emanava de Évrard, a musealização que "traz para a vida" certos objetos do esquecimento para suscitar a transformação no grupo leva a uma libertação — da História, das relações de poder do passado, e da depreciação identitária. Este foi desde o início o propósito maior do Creusot. 


\section{A invenção do "ecomuseu": a evolução de um conceito e de uma experiência}

Ainda que a primeira experiência à qual se atribui este nome tenha sido aquela desenvolvida nos anos 1970, no Creusot, o conceito do "ecomuseu", como assegura Desvallées (informação verbal), ${ }^{19}$ ao contrário do que foi escrito posteriormente (por autores como Octave Debary), não provém da crise industrial do Creusot, uma vez que esta não começara em 1971-1973. Tal conceito está ligado a uma cadeia de transformações na museologia francesa muito mais ampla e complexa que envolveu, com efeito, uma transformação de valores - não apenas no âmbito local, mas na concepção que alguns pensadores e profissionais de museus tinham sobre a prática museológica da época.

O termo "ecomuseu" foi cunhado por Hugues de Varine durante um almoço, em 1971, na avenue de Ségur, em Paris, onde estavam reunidos, além dele, Georges Henri Rivière, como consultor permanente do Icom, e Serge Antoine, conselheiro do ministro do Meio Ambiente, para discutir alguns aspectos da organização da Conferência do Icom daquele ano, que aconteceria em Paris, Dijon e Grenoble, quando se falaria pela primeira vez sobre esse conceito impreciso. Varine e Rivière desejavam que pela primeira vez em uma conferência internacional de tal importância um homem político do primeiro plano ligasse publicamente o museu ao meio ambiente (Varine 1992:449). Sendo assim, após experimentar diversas combinações silábicas entre as palavras "ecologia" e "museu", Varine pronunciou "ecomuseu", dando início à tarefa mais difícil que se seguiria: a de definir tal conceito em termos práticos. Com a utilização do neologismo na conferência de 1971 por Robert Poujade, então primeiro-ministro do Meio Ambiente na França, e o nascimento da Maison de l'Homme et de l'Industrie, no mesmo período, no Creusot, este novo tipo de museu viria a se tornar um protótipo (Desvallées 1992:26). Rivière se consagraria como o principal pensador do termo nos anos seguintes, tendo como base, principalmente, esta experiência.

Na perspectiva que desenvolvera, o meio ambiente seria determinado por uma compenetração da ecologia natural e da ecologia humana, que poderiam até mesmo se confundir (Rivière 1973:26), enfatizando desde o início o caráter relacional da experiência ecomuseal. Em sua prática nos museus, Rivière já não separava natureza e cultura, e mesmo a arte e a etnografia se viam até certo ponto interligadas. A vontade de inserir a ecologia na gramática museal já o perseguia em sua experiência com os museus tradicionais em que atuou. Ao reunir objetos distintos em uma mesma apresentação nos museus etnográficos, Rivière compreendia "as coisas 
reais integradas", isto é, os objetos autênticos agrupados, como objetos que participaram de um mesmo meio, adquiridos em sua integralidade ou reagrupados pela sua função em vida, e a esses agrupamentos ele dava o nome de "unidades ecológicas" (Rivière 1973:28). Eles serviriam, segundo ele, de testemunhos do meio ambiente humano com muito mais intensidade do que os objetos isolados.

Com efeito, a presença dos contextos no museu sempre fez parte da museologia de Rivière, e a oportunidade de alargar a sua prática para a concepção de todo um território como museu iria possibilitar levar o seu projeto de contextualização às últimas consequências. O homem que havia colocado Joséphine Baker em uma vitrine no Musée de l'Homme (Chiva 1985:2) iria agora formular um conceito de musealização das pessoas e das coisas para além das paredes de um museu fechado, em sua definição do ecomuseu.

A primeira definição do ecomuseu, proposta por Jean Blanc (1917-2000), é apresentada, em 1972, aos participantes do colóquio internacional organizado pelo Icom, intitulado "Museu e meio ambiente", que aconteceu em Bordeaux, Istres e Lourmarin. Tal proposição definia o ecomuseu como um "museu específico do meio ambiente", que funcionava como um "elemento de conhecimento" de um conjunto de relações no espaço através do desenvolvimento histórico dessas relações (Blanc 1972 apud Gerbaud 2000:177). Tendo tomado conhecimento das ideias disseminadas por Jean Blanc desde o fim da década de 1960, Rivière havia apresentado até então uma visão mais "clássica", sobretudo porque amplamente baseada no modelo dos museus a céu aberto do norte da Europa ${ }^{20}$ perfeitamente claros em seus princípios. Pouco tempo depois, ele assumiria que o modelo dos museus do norte, como os escandinavos que ele conhecia bem, não se aplicava ao contexto francês em razão da diversidade existente nas províncias francesas.

Em outubro de 1973, Rivière publica a primeira versão de sua "definição evolutiva". Nela, ele caracteriza o ecomuseu como um "museu ecológico", um "instrumento de informação e de tomada de consciência", já considerando a sua evolução permanente "da qual a população participa" (Rivière 1992 [1971-1980]:440). Na definição de 3 de junho de 1978, ele considera o ecomuseu como uma "estrutura nova, experimentada e concretizada, inicialmente, nos parques naturais franceses", entre 1968 e 1971, mas que já se desenvolvia em outros territórios como um "laboratório de campo" (Rivière 1992 [1971-1980]:442) que podia tomar formas diversas. Finalmente, em sua última versão - e a mais conhecida, atualmente - apresentada no Creusot, e depois em Paris em 1980, Rivière define o ecomuseu como laboratório, como conservatório e como escola, e coloca em primeiro plano a diversidade das populações que fazem dele o seu espelho (Rivière 1985 [1980]:183). 
O ecomuseu é previsto como um instrumento por meio do qual as populações podem se tornar, elas mesmas, objetos de sua investigação. Ele é, portanto, segundo a perspectiva desenvolvida por Rivière, um instrumento de autoconhecimento para a prática de uma museologia experimental com base no patrimônio local, visto como um conjunto integrado. Por sua vez, Varine se voltava para a estruturação do ecomuseu com base na população. Estas duas visões iriam se complementar. Para Varine, o novo museu que se imaginava implicava a realização da comunidade urbana enquanto comunidade autoevidente, o que levou, na prática, a uma fórmula de reagrupamento administrativo de coletividades locais vizinhas englobando 16 comunas, isto é, duas cidades de 30.000 habitantes (Varine 1992:450). Em outras palavras, a partir da imaginação destes pensadores da nova museologia, Le Creusot e Montceau-les-Mines seriam reinventadas como uma só comunidade urbana em torno de seu patrimônio e de um museu.

Nos anos que se seguiriam à criação do ecomuseu, essa nova proposta de reformulação do museu visando alterar regimes de valores iria se normalizar por meio de diversos colóquios internacionais e reuniões de especialistas com parte dos habitantes locais. Mas o processo de legitimação e normalização do Écomusée du Creusot seria dificultado pela falta de elementos que lhe permitissem ser reconhecido como museu pelo Estado francês. Por muito tempo, a luta de seus idealizadores pela institucionalização do ecomuseu seria uma de suas principais frentes mobilizadoras. Considerando que a Direção dos Museus da França se recusava a reconhecer um museu que, em seus primeiros anos de existência, não apresentava coleções permanentes, o ecomuseu teve que recorrer a outros ministérios e buscar outras associações fugindo ainda mais do modelo traçado pelos museus tradicionais, e se diferenciando até mesmo de outros tipos de museus de território. Foi então que, voltando-se para a noção de ecomuseu como havia sido evocada por Robert Poujade em Dijon, associando ecomuseu, meio ambiente e ecologia, ele se ligaria ao recém-criado Ministério do Meio ambiente. ${ }^{21}$

Para além de sua interdisciplinaridade - que possibilitava a musealização integral do patrimônio - a especificidade do ecomuseu passa sobretudo pela definição daquilo que está no coração das suas ação e organização: a comunidade. Mas quem é essa coletividade indefinida? Quem se faz representar nela, e para quem o ecomuseu é feito? Estas foram questões fundamentais para os pensadores do ecomuseu em suas primeiras tentativas de colocá-lo em prática.

Se o ecomuseu é a comunidade, a questão do público, de início, foi descartada da concepção de Varine. Ainda que o ecomuseu pudesse abrigar um museu tradicional em seu interior — como aconteceria no Creusot e em 
diversos outros lugares - estes dois tipos de museus existentes no mesmo espaço não poderiam ser confundidos. Isto porque, diferentemente do museu tradicional, o ecomuseu não tinha visitantes, ele deveria ter atores (Varine 1992:459). Ainda que possa parecer ilusória a concepção da automuseologia, em que uma coletividade atua como gestora do seu próprio patrimônio e é o seu público, esta ideia estava no centro da proposta do ecomuseu em seus primeiros estágios de existência.

A ideia de que ecomuseus não são feitos para visitantes, mas para a própria comunidade, ela mesma musealizada, assombrou na prática as diversas aplicações deste termo em diferentes contextos. De fato, esta acepção não se vê enfatizada na definição de Rivière - ainda que tenha sido um ponto fundamental da teoria desenvolvida por Varine. Ao contrário do que pensava este último, para Rivière, a perspectiva de um público externo - real ou imaginado coletivamente pela comunidade - sempre esteve presente em sua abordagem dos ecomuseus. Ao conceber museograficamente a exposição permanente do Château de la Verrerie, inaugurada no Creusot em 1974, composta de objetos do patrimônio comunitário datando de diversos períodos da história local, Rivière é levado a pensar um circuito de visitação que incluía a granja, a escola, os ateliês e as minas, circuito este concebido para receber um público variado, de dentro e de fora da comunidade.

A comunidade é um conjunto complexo de atores que se inventam como gestores, conservadores ${ }^{22}$ e, ocasionalmente, como público do museu. Nos museus comunitários, são atores todos aqueles que, ao mesmo tempo, vivem e fazem da vida objeto musealizado, ou patrimônio que é simultaneamente vivido e observado no presente. "O ecomuseu nasce, então, de uma análise precisa da comunidade em sua estrutura, em suas relações, em suas necessidades" (Varine 1992:458), análise que deve ser feita pelos próprios membros dessa comunidade. Mas qual é a força que mobiliza a "comunidade"?

Um dos grandes mitos do ecomuseu do Creusot, pode-se dizer, é o da participação. Quando em 1976 Mathilde Bellaigue se encarregou de fazer o recenseamento da população local, trabalho que teve a finalidade de estabelecer quem estaria disposto a se engajar no projeto do ecomuseu, ela constatou que a "participação" era um desafio a ser suplantado cotidianamente pelos profissionais envolvidos na organização e na animação do Creusot. ${ }^{23}$ "Mobilizar a comunidade", engajar as pessoas na sua própria performance museal a ser inventada, se revelaria o calcanhar de Aquiles da museologia participativa.

Enfrentando todas essas dificuldades, e outras, o ecomuseu foi criado com a intenção de ser um instrumento privilegiado de desenvolvimento comunitário. Ele não visava ao conhecimento e à valorização de um patrimô- 
nio, nem era um simples auxiliar de um sistema educativo ou informativo, nem um meio de progresso cultural e de democratização das obras humanas (Mairesse 2002:112). Politicamente, ele tinha como objetivo maior romper com o jogo de poder estabelecido em uma comunidade, tornando a totalidade da população consciente de sua autonomia e de seu próprio desenvolvimento. Neste sentido, o ecomuseu é um instrumento de apropriação patrimonial, por meio do qual é possível repararem-se danos do passado e reformularem-se as próprias narrativas em que as pessoas estão historicamente inseridas e a partir das quais se constroem os valores do grupo. O que conta nesses museus, em última instância, é a mensagem e o seu destino, isto é, são "os homens envolvidos pelo ato de musealização no sentido mais amplo" (Desvallées 1992:24).

\section{Os antecedentes da "nova museologia" ou a museologia experimental}

Segundo André Desvallées, o movimento reconhecido como "nova museologia"24 nasceu na França entre 26 de fevereiro de 1982, quando uma assembleia da Associação Geral dos Conservadores Franceses provocou uma reação de desconforto nos mais progressistas, e 26 de agosto de 1982, quando um grupo de conservadores apresentou, em Marselha, o estatuto de uma nova associação que receberia o nome de Muséologie Nouvelle et Expérimentation Sociale ${ }^{25}$ (MNES). Esta, por sua vez, pouco lembrada na historiografia do movimento, se baseava em ideias já disseminadas por alguns críticos da museologia francesa na época e, sobretudo, nos pensamentos de Rivière e Varine. No grupo fundador do MNES, que representaria o ponto de partida para a oficialização do que viria a ser o Movimento Internacional para uma Nova Museologia (Minom), estavam Évelyne Lehalle (primeira presidente do MNES e conservadora do Musée d'Histoire de Marseille $\left.{ }^{26}\right)$, Marie-Odile de Barry (que atuaria no museu do Creusot), Françoise Wasserman (que foi a segunda presidente do MNES e criaria o Écomusée de Fresnes, nas proximidades de Paris), entre outros membros. Este seria um ponto de partida tímido para um movimento que ganharia proporções internacionais, e seus membros iniciais pouco escreveriam sobre a suposta nova museologia que ousavam criar, cuja teoria ainda se encontrava indefinida.

O contexto em que se inventava - na Europa, em primeiro lugar, e depois no restante do mundo - a noção de "ecomuseu" foi permeado por uma série de acontecimentos que levaram a uma nova forma de se pensar a museologia. Os pontos de partida para a nova museologia que se ensaiou nas três últimas décadas do século XX são abundantes, porém descentra- 
lizados. Entre eles estão, por exemplo, um colóquio sobre "Museu e meio ambiente", que aconteceu na França em setembro de 1972, ou a célebre mesa redonda do mesmo ano, entre maio e junho, em Santiago do Chile, organizada pela Unesco para discutir o "Papel do Museu na América Latina" (Desvallées 1992:16). Desvallées remonta à criação, nos anos 1960, dos primeiros museus in situ dos parques naturais e, mais tarde, ao próprio conceito do ecomuseu, que foram as expressões práticas do pensamento teórico que vinham sendo desenvolvidas por Rivière e Varine. No contexto norte-americano, o movimento também teve antecedentes, como o seminário sobre museus de vizinhança (neighborhood museums), em novembro de 1969, nos Estados Unidos, e um seminário sobre o "papel do museu na coletividade", organizado no Bedford Lincoln Neighborhood Museum do Brooklyn, do qual participou John Kinard, fundador, em 1967, do museu de vizinhança no bairro de Anacostia, em Washington. ${ }^{27}$

Há, finalmente, quem atribua o verdadeiro início da nova museologia à $9^{\text {a }}$ Conferência Geral do Icom, de 1971, em que se tratou do tema "o Museu a serviço dos Homens, hoje e amanhã", tendo sido enunciado pela primeira vez o termo "ecomuseu", em 3 de setembro, em Dijon, por Robert Poujade (Desvallées 1992:17). Mais do que o lançamento de um conceito desconhecido, este foi um momento de encontro entre pensadores dos hemisférios norte e sul, que trocaram experiências sobre suas práticas e começaram a cogitar a possibilidade de uma verdadeira descolonização dos museus. Participou desta conferência, entre outros atores da prática museal, ${ }^{28}$ Stanislas Adotevi, representante do Dahomey, que colocou em questão todos os fundamentos do museu, não somente em nome dos povos do "terceiro" e "quarto" mundos, para os quais o museu significaria pouco, mas também em nome de todos os países industrializados. Juntamente com as declarações deste último, perturbou o público a frase de Jean Chatelain, então diretor dos museus da França e presidente do comitê francês do Icom: "no Louvre, nós não precisamos de animação, nós temos a Gioconda e a Vênus de Milo". ${ }^{29}$ Tal declaração denunciou uma discrepância aguda entre os discursos de profissionais de museus nas diferentes partes do mundo, bem como um conflito de valores latente que definiria a museologia dos anos seguintes.

Fato é que no momento em que a discussão sobre o ecomuseu eclodiu, principalmente na Europa, alguns países do outro lado do Atlântico já vinham experimentando casos "alternativos" de museus, aparentemente bem-sucedidos e que, por isso, começavam a ser divulgados. Os exemplos não eram numerosos, mas receberam destaque entre os especialistas, como foi o caso do Anacostia Museum, ${ }^{30}$ nos Estados Unidos, e da Casa del Museo, no México. Ao mesmo tempo, na França, eram criados os primeiros museus 
a céu aberto nos parques naturais de l'Armorique (Finistère) e de Landes, que iriam ser considerados pelos teóricos da nova museologia como os primeiros ecomuseus (termo que então ainda não havia sido cunhado). Assim, a ideia do ecomuseu iria apenas coroar uma transformação inevitável que ganharia, tanto na teoria quando na prática experimental, proporções até então inimagináveis no processo de estruturação de uma nova "gramática axiológica" para o campo museal.

\section{A "moda" do ecomuseu: a importação de uma experiência que se fez global}

Se o caso particular do Écomusée du Creusot esteve balizado, nos anos 1970, pela constituição de uma gramática museal como uma nova gramática axiológica para o patrimônio local, é possível afirmar que, de forma mais ampla, a noção do ecomuseu representou uma mudança de valores na museologia. Mantendo-se como "uma escola viva de contestação" (Desvallées 1992:15), a nova museologia se tornou, particularmente na França, como apontou Desvallées, um movimento de resistência a certos "desvios" de sentido do que poderia ser a museologia e a museografia. ${ }^{31} \mathrm{Um}$ dos objetivos daqueles que decidiram organizar as novas ideias que se faziam perceber em museus no mundo todo, formando uma ideologia própria, era operar uma mudança profunda nas mentalidades dos profissionais de museus, o que se refletiria na prática museológica. Em 1983, um grupo de teóricos do Comitê Internacional de Museologia do Icom (Icofom) ${ }_{1}^{32}$ reunidos em Londres durante a Conferência Geral da organização, fez um pronunciamento público que já previa a estruturação de um movimento que partia de membros daquele comitê.

Em 1984, a Declaração de Quebec deu força às novas ideias, criando o Movimento Internacional para uma Nova Museologia (Minom). Em 1985, no II Atelier da Nova Museologia, em Lisboa, o Movimento seria oficializado. Tomando por princípios básicos aqueles traçados anteriormente em Quebec, e tendo como premissa a ideia do museu integral ${ }^{33}$ proposta na mesa redonda de Santiago, o Minom tornou ainda mais evidente o processo de transição que já vinha de fato acontecendo nos museus e trouxe para a cena da museologia internacional o que foi chamado de uma "museologia social", ou seja, a transição para um museu mais aberto às sociedades humanas e aos problemas sociais. Esta abertura, que já vinha ocorrendo desde o final do século XIX, ganha então nome e se institucionaliza na teoria que iria debruçar-se sobre a prática existente. O modelo do ecomuseu passa a ser divulgado pelos quatro cantos do mundo, agora quase como uma bandeira 
política. Como um conceito endógeno do campo da museologia, ele começa a despertar o interesse de pensadores ligados a outros campos do saber, como as ciências sociais, a antropologia e a história.

Nos anos 1980, como afirma Desvallées, "o ecomuseu estava na moda" (informação verbal) ${ }^{34}$ e ele seria o principal assunto de discussão em instâncias como o Minom e o Icofom que, nesse momento, não representavam correntes contrárias de pensamento, mas compartilhavam dos mesmos atores da museologia teórica internacional, bem como das mesmas preocupações. Pouco a pouco o Minom demarcaria um campo de debates voltado para uma "museologia social", que vinha ganhando cada vez mais adeptos. Em 1986, este grupo teve o seu número de membros dobrado. Nessa época dá-se a mobilização de países que o movimento ainda não havia alcançado, com destaque para a penetração entre os anglófonos e entre os países africanos. A descentralização almejada até mesmo na organização interna do Minom resultou, desde o início, em muitos aspectos, em uma má comunicação entre seus membros e entre outros tantos não membros que buscavam informações sobre as mudanças que o "grupo central", formado principalmente por europeus e canadenses, tentava disseminar.

A partir da segunda metade da década de 1980 o movimento da nova museologia ganha uma dimensão mais marcadamente intercontinental. Quando, no final dessa década e no início da seguinte, o Minom conquista uma vasta aderência entre os portugueses e espanhóis, as experiências com museus ditos "sociais" passam a ser disseminadas de maneira ampla, e são evidenciados diversos tipos de "museus comunitários" — não apenas os ecomuseus, mas também outros modelos de museologia comunitária, como aqueles descendentes dos museus locais ou os que se inspiraram nos museus de vizinhança, como os que se espalharam nos Estados Unidos a partir dos anos 1960. Esta vertente ampla do movimento chega, a partir da década de 1990 e mais fortemente nos anos 2000, ao Brasil e a outros países da América do Sul, adquirindo, então, as suas próprias características locais, de acordo com os embates políticos endógenos e as formas particulares de se conceberem os seus ditos "museus comunitários".

É possível concluir que aquilo que levou o ecomuseu a se espalhar pelo mundo no final do século XX e ainda no presente não foi o seu entendimento como um modelo, mas sim a aplicação em diferentes contextos sociais de uma nova concepção do processo de valoração do patrimônio. Esta reinterpretação do ecomuseu em países periféricos como o Brasil permitiu o seu uso como um serviço museológico eficaz nos processos de revaloração de grupos marginalizados e como instrumento de luta política a ser usado pelos grupos para desestabilizar posições hegemônicas a partir da institucionalização de novos "regimes de qualificação". 
A nova museologia foi, com efeito, um fenômeno histórico que atuou como a expressão de uma mudança prática no papel social dos museus. É também uma estruturação de valores, ou seja, qualquer coisa de mais subjetivo, mas que pode ser relativamente objetivada pela análise das ações e do discurso dos seus principais atores e idealizadores. Para Maure (1995), ela é a expressão de uma ideologia específica. O "novo museu" proposto como a sua principal forma de expressão se mostrou, por um lado, como um instrumento eficaz de mudança de valores e, por outro, como uma estrutura passível de ser apropriada pelos idealizadores das mudanças apresentadas, tanto para o seu benefício quanto para o benefício dos grupos sociais envolvidos.

Os primeiros ecomuseus foram criados como estruturas maleáveis sujeitas a transformações no tempo de acordo com a evolução das sociedades e as transformações necessárias do fazer museológico. A maior ruptura que se deu com a experiência do Écomusée du Creusot não foi com os modelos de museus anteriores, mas sim na invenção de um "não modelo" de museu que pode ser aplicado a diversos contextos sociais, tomando as formas e os contornos que desejam as pessoas que habitam o espaço por ele ocupado. Neste sentido, ainda que pareça contraditório sem ser, o ecomuseu, um tipo de museu local, é hoje um museu globalizado, pois se espalhou pelo mundo, assumindo formas distintas, mas sem se reproduzir como um modelo acabado.

Na maior parte dos contextos em que foi colocado em prática, o ecomuseu levantou questões sobre o próprio fazer museológico. Tais questões levaram ao pensamento crítico sobre os processos de avaliação realizados pelos museus ao selecionarem certos objetos como patrimônio. Ao engendrar novos regimes de atribuição de valor, ou de valoração, o ecomuseu deflagra a arbitrariedade das escolhas sobre o patrimônio feitas pelos museus, a implicação das emoções patrimoniais e tudo aquilo que há de subjetivo na seleção dita "oficial" colocada em prática pelos museus tradicionais. Mais do que inverter a lógica dos regimes de qualificação, ao evidenciar que estes são construídos socialmente, o ecomuseu torna visível a gramática museal como uma gramática axiológica.

Recebido em 19 de julho de 2014

Aprovado em 10 de dezembro de 2014

Bruno Brulon é professor adjunto do curso de Museologia da Universidade Federal do Estado do Rio de Janeiro (Unirio). E-mail: < brunobrulon@gmail.com> 


\section{Notas}

* O presente artigo é resultante da tese de doutorado Máscaras guardadas: musealização e descolonização, orientada pela profa. Dra. Lygia Segala, e defendida, em 2012, no Programa de Pós-Graduação em Antropologia (PPGA) da Universidade Federal Fluminense (UFF). Tal pesquisa contou com um estágio doutoral na École des Hautes Études en Sciences Sociales, em Paris, financiado pelo Programa de Doutorado Sanduíche no Exterior (PDSE) da Capes.

1 "Um ecomuseu, não é um museu como os outros" (tradução nossa). Georges Henri Rivière, "L'Écomusée". CRACAP, n. 2-3:15.

${ }^{2}$ Inicialmente, os principais foram França, Canadá, Portugal e Itália. Progressivamente, as experiências de ecomuseus se disseminaram pelo mundo, desenvolvendo-se de forma expressiva em países como o Brasil, o México, a China e o Japão, além de países que aderiram a este modelo mais adiante, como a Índia e o Senegal.

${ }^{3}$ É o caso, por exemplo, ainda no início dos anos 1960, da iniciativa do Museu Nacional de Antropologia do México, aclamado como uma das mais consideradas instituições de seu tempo, que adotou a lógica da abertura do museu em direção às escolas. Outra iniciativa mexicana que ganharia o nome de Casa del Museo teve seu projeto experimental lançado na mesma década, focando-se em áreas populares de forma descentralizada, e mobilizando diferentes públicos a se confrontarem com os costumes dos habitantes da época pré-hispânica (Mairesse 2002:105).

${ }^{4}$ Termo utilizado pelos próprios idealizadores do museu e seus principais agentes para se referirem ao grupo de habitantes do Creusot e da vizinhança, que seria mais tarde instituído em âmbito municipal.

${ }^{5}$ Centre d'Action Culturelle (CAC) de le centre de Loisirs, Arts, Rencontres et Culture.

${ }^{6}$ Como atesta Bernard Paulin, encarregado das atividades culturais da cidade do Creusot, em entrevista à Octave Debary (Debary 2002:29).

${ }^{7}$ Centre National de Recherche d'Animation et de Création pour les Arts Plastiques.

${ }^{8}$ Categoria empregada na França para distinguir museus que não se definem como museus de arte. Segundo Lévi-Strauss, a característica própria dos "museus de sociedade" é criar um programa reflexivo fundado sob os princípios das ciências sociais (Lévi-Strauss in Chiva 1992 apud Gorgus 2003). São classificados como "museus de sociedade" os museus de etnologia, os museus regionais e locais e, por vezes, os ecomuseus.

${ }^{9} \mathrm{O}$ pedido para que Varine participasse do projeto do que viria a ser a primeira experiência de ecomuseu veio originalmente da municipalidade do Creusot, e ele foi 
até lá, primeiramente, para fazer uma avaliação. Falou com os sindicatos dos trabalhadores e, quando lhes apresentou uma ideia de museu clássico da época, eles não se mostraram interessados (Varine 1992).

${ }^{10}$ Entrevista realizada em Paris em 5 de abril de 2012.

${ }^{11}$ Antes disso, a riqueza mineral do solo da região já era explorada através da instalação de uma fundição de canhões entre 1782 e 1785. Em 1786 é transferida de Sèvres para o Creusot a Manufatura dos Cristais da rainha Maria Antonieta (Debary 2002:19).

${ }^{12}$ O museu do Creusot ganharia o nome de Musée de l'Homme et de l'Industrie.

${ }^{13}$ Desde a criação do Cracap, no final da década de 1960, Rivière foi um de seus primeiros membros, ao lado de Évrard, mas ele só passou a atuar de forma sistemática no projeto do ecomuseu do Creusot depois que Varine já cumprira o papel de estruturar o museu (Gorgus 2003:263).

14 "Museu explodido", em português (Varine-Bohan 1973:242-249).

${ }^{15}$ Movimento de descolonização das práticas museológicas que aconteceu na Europa, inserido no movimento mais amplo de uma descolonização das mentalidades coloniais e das práticas sociais (Brulon Soares 2012). O termo "descolonização da museologia" foi pensado neste sentido por Hugues de Varine (2005).

${ }^{16}$ No original: "Les thêatres de la mémoire se dressent comme des tables d'exhumation où le geste patrimonial ne semble conserver de l'histoire que ses restes insacrifiables. Les restes protestent, s'organisent et défient un présent qui s'emploie à les oublier sans cérémonie, sans hommage. L'alchimie patrimoniale prétend conjurer la mort, mais ce recyclage est au fondement d'une économie (un partage des richesses) réduite à n'être qu'une écologie: un partage du reste des richesses".

${ }^{17}$ Entrevista realizada em Paris em 5 de abril de 2012.

${ }^{18}$ Hoje, o Château de la Verrerie é um museu tradicional, que exibe a história dos habitantes do Creusot e a história dos Schneider. O parque dessa antiga residência patriarcal é amplamente utilizado pela comunidade local, como jardim, espaço histórico e lugar de encontro.

${ }^{19}$ Entrevista realizada em Paris em 30 de março de 2012.

${ }^{20}$ Desde que Artur Hazelius, sueco dedicado ao trabalho com museus, criou em 1872 o primeiro Folk Museum da Europa, o Nordiska Museet, pensado como parque popular a céu aberto, renovou a concepção espacial de um museu. A partir do final do século XIX, na Escandinávia, iriam se desenvolver outros museus seguindo este modelo. Neles, em geral, podiam ser visitados diversos tipos de construções rurais, igrejas antigas, fazendas, ateliês espalhados no meio de parques botânicos e zoológicos. Partindo desta concepção de museu que se disseminou no norte europeu, 
o museu a céu aberto de Skansen, na Suécia, inaugurado em 1891, iria colocar em prática um tipo de encenação do passado baseado no rearranjo e na teatralização dos restos materiais tradicionais. Nos museus escandinavos, o que predominava era a cultura como síntese e a encenação de um passado posto em prática de forma teatral, tendo os restos do passado tradicional como cenário (Rivière 1968).

${ }^{21}$ Para Debary, o museu do Creusot jamais foi pensado como ecomuseu no sentido de salvaguardar a natureza, uma vez que isto poderia implicar a substituição da salvaguarda da indústria (Debary 2002:35). Segundo a sua crítica ao ecomuseu, a ecologia era pretexto para uma museografia que, acompanhada pela arte, resultasse em uma "confusão" que atendia aos anseios dos seus gestores. Alguns ecomuseus, todavia, fiéis ao discurso de Robert Poujade de 1971 e ao modelo inicial do museu de Landes (que é considerado, por André Désvallées, como o primeiro ecomuseu, ainda que não levasse este nome), são instituições estreitamente associadas ao meio ambiente e à vida natural e cultural no território, sendo as mais comuns delas aquelas que estão inseridas nos parques naturais.

${ }^{22}$ Não havia, de fato, uma participação de membros da comunidade como "conservadores" no sentido tradicional do termo. Com efeito, sequer havia conservadores, com formação específica nesta área, no momento em que o museu foi fundado o que representava mais um entrave para a sua institucionalização como museu.

${ }^{23}$ Tal trabalho de recenseamento, segundo Bellaigue, partiu das associações já criadas na comunidade do Creusot antes da proposta do museu. Estas associações, assim como as entrevistas com lideranças locais, serviram de canais para apontar quem seriam os atores interessados em participar do projeto de museu. Bellaigue afirma que, por alguma razão, a população do Creusot já apresentava uma organização bastante minuciosa em diversas associações (associação dos mineiros, associação dos agricultores, associações que se ocupavam dos animais, associação para os ciclistas, foto-clube etc.), o que facilitou o contato com as pessoas interessadas (Entrevista realizada em Paris em 5 de abril de 2012).

${ }^{24}$ O termo "nova museologia" foi criado pelo próprio Desvallées, que reclama a sua paternidade. Ele o teria escrito pela primeira vez na Encyclopédie Universalis, em 1981, quando foi convidado para atualizar o artigo "Muséologie", de Germain Bazin, de 1968. Segundo ele, "como era a moda este gênero de título (as novas matemáticas, a nova história, a nova filosofia etc.), eu pensei que seria pertinente denominar assim todas as iniciativas que tinham o sentido de uma renovação dos museus e da museologia". Comunicação por e-mail, 15 de agosto de 2012.

25 "Museologia nova e experimentação social". A MNES seria a antecessora do Movimento Internacional por uma Nova Museologia (Minom).

${ }^{26}$ Museu de História de Marselha.

${ }^{27}$ O termo new museology, entre os autores anglófonos, como difundido no início dos anos 1990, tem o sentido de uma reabilitação de antigos museus ou da 
construção de novos e, neste sentido, o termo se diferencia do seu uso mais conhecido em francês, nouvelle muséologie, ou nova museologia, em português. Atualmente, ele já vem sendo usado por alguns autores norte-americanos para se referirem ao movimento da nova museologia iniciado na França (Desvallées 1992:24).

${ }^{28}$ Entre os quais podemos destacar Duncan F. Cameron, conhecido na América do Norte pelo seu trabalho sobre a linguagem da comunicação do museu, e John Kinard, que expôs o projeto do museu comunitário que havia criado em Washington.

${ }^{29}$ O termo "animação" (animation), recorrentemente usado por Varine, tem o sentido de "dar vida" a um museu ou a um patrimônio, e é constantemente empregado na França para se referir às atividades realizadas nos ecomuseus.

${ }^{30}$ Museu de vizinhança criado em 1967, o Anacostia Neighborhood Museum, em Washington, pertencente à Smithsonian Institution, está localizado no seio de uma comunidade afro-americana de aproximadamente 71 mil habitantes. Esta proposta estava fundada na vontade de líderes de um grupo local de promover na "comunidade" a sua própria história e a história do seu meio. A participação é incentivada e é indispensável na constituição do museu. Embora existente fisicamente na forma de um museu tradicional, com exposições sempre renovadas, ele tem a sua área de atuação ampliada, interagindo com e valorizando todos os tipos de atividades locais, festas típicas, eventos religiosos, encontros da terceira idade, de maneira a integrar a vida dos residentes (Kinard 1972:103).

${ }^{31}$ Termos estes que, até meados dos anos 1970, se confundiam no contexto francês.

${ }^{32}$ Estavam presentes André Desvallées, Mathilde Bellaigue, Vinoš Sofka, Zibniew Stránský, Waldisa Rússio, Tereza Scheiner, Flora Kaplan, entre outros teóricos.

${ }^{33}$ A ideia de "museu integral" foi proposta inicialmente em 1972, na mesa redonda realizada pela Unesco em Santiago do Chile, onde se pretendia debater sobre o papel dos museus da América Latina. Trata-se da ideia de um museu que integrasse as sociedades e o meio em todas as suas relações e que atuasse a partir delas. Desde então, o termo "museu integral" - e suas variações, como a tradução em inglês total museum (museu total) - vem sendo usado para pensar um novo campo de ação para aquelas instituições que se definem, geralmente, como "museus sociais".

${ }^{34}$ Entrevista realizada em Paris em 30 de março de 2012. 


\section{Referências bibliográficas}

BELLAIGUE SCALBERT, Mathilde. 1983. “Territorialité, mémoire et développement-l'Ecomusée de la Communauté Le Creusot/Montceau les Mines". Icofom Study Series, 2:34-39.

. 1989. "Georges Henri Rivière et la genèse de l'écomusée de la Communauté Le Creusot-Montceau-les-Mines". In: Georges Henri Rivière (org.), La muséologie. Textes et témoignages. Paris: Dunod. pp. 164-165.

GERBAUD, Michel. 2000. "Aux origines des écomusées: les premiers pas de Marqueze". Publics \& Musées, $17-$ 18:177-180.

BOLTANSKI, Luc \& THÉVENOT, Laurent. 1991. De la justification. Les économies de la grandeur. Paris: Gallimard. CHAUMIER, Serge. 2004. "Écomusées: entre culture populaire et culture savante". POUR, 181:65-70. Dossier Mémoires partagées, mémoires vivante.

CHIVA, Isac. 1985. "George Henri Rivière: un demi-siècle d'ethnologie de la France". Terrain [en ligne], 5. Disponível em: <http://terrain.revues. org/288>. Acesso em: 06/04/2012.

DEBARY, Octave. 2002. La fin du Creusot ou l'art d'accommoder les restes. Paris: CTHS.

DESVALLÉES, André. 1992. "Présentation". In: André Desvallées; Marie Odile de Barry \& Françoise Wasserman (coords.), Vagues: une antologie de la Nouvelle Muséologie. vol. 1. Collection Museologia. Savigny-le-Temple: Éditions W-M.N.E.S. pp. 15-39.

ESTATUTO do Ecomuseu da Comunidade Urbana do Creusot Montceau les Mines - Musée de l'Homme et de l'Industrie. 1973. Arquivos do Ecomuseu.

ÉVRARD, Marcel. 1974. "Rencontre nationale sur l'animation des arts plastique en France, Le Creusot". Cracap, 1:1.

. 1976. "L'Écomusée de la communauté urbaine le Creusot-Montceau les Mines". Cracap / Informations, 2-3:9-14. . 2010 [1980]. "Exemple". Milieux, 2. In: Divers. Recueil de préfaces pour la revue Milieux / 1980-1984. Le Creusot: Écomusée Creusot-Montceau.

GORGUS, Nina. 2003. Le magicien des vitrines. Le muséologue Georges Henri Rivière. Paris: Éditions de la Maison des Sciences de l'Homme.

HEINICH, Nathalie. 2009. La fabrique du patrimoine. De la cathédrale à la petite cuillère. Paris: Éditions de la Maison des Sciences de l'Homme.

. 2012. "Les émotions patrimoniales: de l'affect à l'axiologie". Social Anthropology/Anthropologie Sociale, 20(1):19-33.

KINARD, John R. \& NIGHBERT, Esther. 1972. "The Anacostia Neighborhood Museum, Smithsonian Institution, Washington, D.C.". Museum, XXIV(2):103108. The fine arts museum of Expo'70, Osaka/ Paris: Unesco.

MAIRESSE, François. 2002. Le musée temple spetaculaire. Paris: Presses Universitaires de Lyon.

MAURE, Marc. 1995. "La nouvelle muséologie-qu' est-ce-que c' est?". Icofom Study Series, 25:127-132.

RIVIĖRE, Georges Henri. 1968. "Musées et autres collections publiques d'ethnographie". In: Jean Poirier (dir.), Ethnologie générale. Paris: Gallimard. pp. 472-493.

. 1973. "Rôle du musée d'art et du musée des sciences humaines et sociales". Museum International, XXV(1/2):2644. Paris: Unesco. . 1976. "L'Écomusée". Cracap/Informations, 2-3:15. 
• 1992. "L'écomusée, un modèle évolutif (1971-1980)". In: André Desvallées; Marie Odile de Barry \& Françoise Wasserman (coords.), Vagues: une antologie de la Nouvelle Muséologie. vol. 1. Collection Museologia. Savigny-le-Temple: Éditions W-M.N.E.S. pp. 440-445.

1985 [1980]. "Définition évolutive de l'écomusée". Museum, XXXVII(4): 182-183.

VARINE-BOHAN, Hugues de. 1973. "Un musée éclaté: le Musée de l'Homme et de l'Industrie". Museum, XXV(4):242-249. . 1992a. "L'écomusée (1978)". In: André Desvallées; Marie Odile de Barry \& Françoise Wasserman (coords.), Vagues: une antologie de la Nouvelle Muséologie. vol. 1. Collection Museologia. Savigny-le-Temple: Éditions W-M.N.E.S. pp. 446-487. . 1992b. Anais do $1^{\circ}$ Encontro Internacional de Ecomuseus. Rio de Janeiro: Prefeitura do Rio de Janeiro/Secretaria Municipal de Cultura, Turismo e Esporte. Mimeo.

2005. "La décolonisation de la muséologie". Nouvelles de l'Icom, 3:3. 


\section{Resumo}

A descolonização dos museus, à qual se referiram alguns museólogos que pretendiam fazer uma museologia de vanguarda nos anos 1960 e 1970, diz respeito a um conjunto de conceitos que tinham por objetivo revolucionar a prática museológica do final do século XX. Aideia do "ecomuseu", como o protótipo para uma prática museológica experimental, é "inventada" no bojo dessa transformação. A partir da análise histórica do Écomusée du Creusot Montceau-les-Mines, criado na França, na região da Borgonha, em 1974, este artigo investiga o processo de mudança da "gramática axiológica" local, engendrado pela gramática museal, bem como traça uma reflexão mais ampla sobre a própria mudança de valores atravessada pela museologia internacional a partir do conceito do "ecomuseu" e do movimento da nova museologia.

Palavras-chave Ecomuseu, Nova museologia, Museologia experimental, Écomusée du Creusot,Valores.
Abstract

The decolonization of museums, an important idea for some museologists from the 1960's and 1970's who wanted to create an avant-guard museology, relates to a set of concepts that hoped to revolutionize museological practice at the end of the $20^{\text {th }}$ century. The idea of the "ecomuseum" as a prototype for experimental museological practice emerged in the midst of this transformation. Through a historical analysis of the Écomusée du Creusot Montceau-les-Mines, created in the French region of the Bourgogne in 1974, this article investigates changes in the local "axiological grammar" as engendered by museum grammar. It also reflects more widely on the changes in values in international museology effected by the concept of the "ecomuseum" and the new museology movement.

Key words Ecomuseum, New museology, Experimental museology, Écomusée du Creusot, Values. 